\title{
Change in Knowledge of and Adherence to the Low- Sodium Diet in Patients with Heart Failure after Nutrition Education by a Registered Dietitian Nutritionist
}

\author{
Candice A. Tan, Sarah J. Holland, Marisa E. Mozer, Kali E. Sarcinella, Christy C. \\ Tangney, Heather E. Rasmussen*
}

\section{ABSTRACT}

Nutrition intervention by a registered dietitian nutritionist (RDN) is effective in improving patients' knowledge or adherence to low-sodium diet (LSD, <2,000 mg/d); however, changes in knowledge and adherence in heart failure (HF) patients have not been simultaneously assessed in the same study period Therefore, the objective of the present study was to identify both HF patient sodium knowledge and adherence to the LSD before and after an education session with an RDN. A quasi-experimental study with a one-group, pre-test post-test design was conducted. An RDN conducted a 15-minute individualized nutrition education regarding the LSD at the initial visit. Sodium knowledge was measured by the Parkland Sodium Knowledge Test, and sodium intake was measured

Heart failure (HF) prevalence is increasing, with an estimated 6.2 million Americans $\geq 20$ years of age with HF between 2013-2016, up from 5.7 million from 2009-2012. ${ }^{1}$ Among the risk factors for HF; hypertension, obesity, cardiovascular disease, and diabetes are all modifiable through diet. ${ }^{2-6}$ Additionally, in an effort to improve HF-associated symptoms and quality of life, a low-sodium diet (LSD) is recommended.. The Heart Failure Society of America recommends a daily sodium restriction of 2,000-3,000 mg for symptomatic HF patients, and less than $2,000 \mathrm{mg} /$ day for those with moderate to severe HF. ${ }^{7}$ The American College of Cardiology Foundation/American Heart Association recommends no more than $1,500 \mathrm{mg}$ of sodium a day for stage $\mathrm{A}$ and $\mathrm{B}$ and less than $3,000 \mathrm{mg} /$ day for stage $\mathrm{C}$ and $\mathrm{D}$ for symptom improvement. ${ }^{8}$ While specific recommendations differ between associations, sodium restriction remains a key therapeutic recommendation for this condition.

While the LSD is a component of non-pharmacological regimens for HF, lack of patient knowledge related to a LSD and low adherence to by a 29-item sodium-specific food frequency questionnaire created by NutritionQuest ${ }^{\oplus}$ at both the initial and follow-up visits. A total of 71 patients were educated on the LSD and assessed for changes in sodium knowledge and intake at their next visit. Most patients were middle aged, obese, male, and non-Hispanic Black with an education level of greater than 12 years. At the initial visit, the majority of patients were considered knowledgeable but not accordant to the LSD. Following RDN education, sodium knowledge significantly improved and sodium intake significantly decreased. RDNs should be included as members of the HF multidisciplinary team to increase sodium knowledge and reduce sodium intake through individualized nutrition education.

a sodium restriction is common. ${ }^{9-11}$ Sodium knowledge, such as correct use of a nutrition facts label, may be important to improve adherence to the LSD. However, few studies have specifically tested HF patients' sodium knowledge. The Parkland sodium knowledge test has been used as an indicator of sodium knowledge through container sorting, label reading, and knowledge of the sodium recommendation. ${ }^{12,13}$ Using these constructs, the majority of HF patients had low sodium knowledge defined as scores less than 3 (range of 0-10). However, individual patient sodium knowledge was not simultaneously compared to sodium intake in these studies.

Adherence to the LSD may be assessed through 24-hr urine collection, but patient burden prohibits this as routine in clinical practice. Sodium adherence has also been assessed by 3-day food records $;{ }^{14}$ however, practical limitations exist regarding patient completion of food records in a clinic setting. Evidence for adherence has largely been assessed through one-question responses asking whether patients follow a LSD or not; ${ }^{10,15,16}$ HF patient perception of their diet accordance 
may not accurately represent actual intake. ${ }^{17}$ In addition, while an RDN-led nutrition intervention was shown to be effective in improving HF patients' knowledge ${ }^{13}$ or adherence to the LSD, ${ }^{18}$ knowledge and adherence and the relation between the two have not been assessed in the same study. In addition, standardized tools feasible for use in the clinic setting by an RDN have not been used to thoroughly assess both HF patient knowledge and intake in this population. Therefore, the objective of this study was to determine the HF patient sodium knowledge and adherence to the LSD before and after an education session with an RDN using standardized questionnaires.

\section{RESEARCH DESIGN AND METHODS}

\section{Participants}

This study was a quasi-experimental, one-group, pre-test post-test design using a convenience sample of chronic HF patients at an outpatient $\mathrm{HF}$ clinic in Chicago, Illinois, USA with a New York Heart Association (NYHA) functional class of I to IV. Patients were included if they were over 18 years old and had a HF diagnosis. Patients were excluded if they were non-English speaking, previously had a heart transplant or were currently on the heart transplant list (to exclude those with previously required RDN counseling), were cognitively impaired, or declined participation. Rush University Medical Center Institutional Review Board (IRB) approval was received prior to data collection. The present study was conducted according to the provisions of the Declaration of Helsinki.

\section{Measures}

\section{Sodium knowledge}

The Parkland Sodium Knowledge Test (Parkland) is a questionnaire designed to assess sodium knowledge, with four primary components: questions targeting sorting food containers by sodium content, reading a Nutrition Facts label, and identifying the sodium guideline for HF patients, as well as a brief food frequency questionnaire (FFQ). ${ }^{19}$ The sodium knowledge score is calculated as +5 points if the patient is able to sort all 12 food containers correctly into six high- ( $\geq 300 \mathrm{mg}$ sodium/serving) and six low- (<300 mg sodium/serving) sodium categories, +2 points if the patient is able to read the label for sodium content accurately, and +3 points if the patient knows the sodium guideline of 2,0003,000 mg/d. The Parkland knowledge score can range from 0 (lowest knowledge) to 10 (highest knowledge), with possible scores of $0,2,3,5,7,8$, and 10. A score of 0 to 3 indicates the patient was not knowledgeable about the LSD, and a score of
5 to 10 indicates the patient was knowledgeable. ${ }^{12}$ The food-frequency questionnaire (FFQ) section of the Parkland was excluded for this study as the NutritionQuest ${ }^{\odot}$ Block Sodium Screener (Block sodium screener), a more comprehensive tool, was used. In a previous study by Kollipara et al, the Parkland was considered a reliable marker of sodium intake $(\kappa=0.64)$ as there was a significant relationship between its assessment of high-sodium food intake and dietary sodium knowledge as assessed by an independent method. ${ }^{19}$ In the current study, internal consistency of the behavioral capacity (2 items; sorting containers and reading the Nutrition Facts label) of the Parkland was performed, with a Cronbach's alpha of 0.53 . Additionally, construct validity of the Parkland tool was assessed in the current study by comparing the scores by prior RDN education. Those who had prior education from an RDN had a median (IQR) Parkland score of $7(3,10)$, while the group without prior RDN exposure had a score of $5(2,10)$ $(P=0.04)$.

\section{Sodium Intake}

The Block Sodium Screener developed by NutritionQuest ${ }^{\odot}$ is a self-administered 29-question FFQ designed to assess sodium intake over the past month. The questionnaire targets commonly eaten high-sodium food categories (eg, bacon or breakfast sausage, including in breakfast sandwich). Respondents are asked to mark how frequently they consumed the food per week with a score between 0 (least frequent) to 4 (most frequent). For the current study, "Rarely or never (0)" or "1-2 times/ week (1)" was considered not frequent consumption; "3-4 times/week (2)," “5-6 times/week (3)," or "everyday (4)" was considered frequent consumption. Portion sizes of certain food categories were asked, with a possible score between 0 (small) to 2 (large). The total screener score, with a possible maximum score of 67 points, was used to calculate the patient's estimated sodium intake in $\mathrm{mg} / \mathrm{d}$ using sex- and age-specific predictive equations provided by NutritionQuest $^{\circ}$. If the patient consumed $<2,000 \mathrm{mg} / \mathrm{d}$, the patient was considered accordant (initial visit) or adherent (follow-up visit after education). These terms will be used accordingly in the subsequent text, with accordant used at baseline as prior education was unknown.

\section{Barriers}

Each patient was asked to identify perceived barriers to following the LSD by selecting from a list of potential barriers. Barriers were chosen based on the literature with modification. ${ }^{10,14}$ Barriers to consuming a LSD included the following: 
1) low-sodium food does not taste good, 2) eating outside of my home is difficult, 3) I do not know how to cook low-sodium meals, 4) buying low-sodium foods are expensive, 5) I do not understand why I should follow a LSD, and 6) I do not feel that eating foods high in sodium will harm my health.

\section{Data Collection and RDN Intervention}

At the initial visit, the investigator (MM, KS, CT) administered the Parkland orally to the patient and then asked the patient to complete the Block sodium screener and the barrier checklist on paper. If the patient was unable to complete the Block sodium screener on paper, the RDN assisted the patient by orally administering the screener. The RDN then conducted a 15-minute individualized education session based on patient questionnaire responses and created patient-centered goals. All patients were given educational materials including information on low-sodium nutrition therapy, foods to avoid and alternatives, label reading, eating out, use of spices, and low-sodium recipes. The RDN discussed the materials that pertained to the needs of the patient. The patient was eligible for follow-up with the RDN after one month.

At the follow-up visit, the investigator re-administered the Parkland and Block sodium screener in an effort to identify changes in sodium knowledge and intake from baseline. The patient then identified changes in barriers. Additional individualized recommendations were then made based on patient responses.

\section{Statistical Analyses}

All statistics were analyzed using IBM SPSS statistics software (Version 19.0; Armonk, NY). A $P$ value of $<0.05$ was considered significant. Descriptive statistics (mean $\pm \mathrm{SD}$, median (IQR) and frequency) were used to describe sample characteristics. If normally distributed, parametric tests were used; if not normally distributed, non-parametric tests were used. $\chi^{2}$ tests were used to detect differences in demographic categories (gender, race, education level) and sodium accordance/ adherence between knowledge groups (high versus low). Differences by median time between patient visits ( $<5$ months versus $\geq 5$ months) and difference by prior RDN education (yes versus no) were assessed using Mann Whitney $\mathrm{U}$ tests. To examine whether changes in sodium knowledge and sodium adherence were significant, Wilcoxon Signed Rank tests (sodium knowledge) and paired t-tests (sodium adherence) were performed, respectively. McNemar tests were performed to assess difference between the initial and follow-up visits for components of the Parkland, food categories of the Block sodium screener, and identified barriers. Data are presented for only those who completed both visits.

\section{RESULTS}

A total of 425 patients with heart failure were screened, and 168 patients were excluded (Figure 1) Of the 152 patients approached, 114 patients consented and completed the initial visit. A total of 71 patients completed the follow-up visit and were included in the final analysis.

\section{Baseline characteristics}

Baseline demographic characteristics of the sample $(n=71)$ are described in Table 1 . The patients were middle aged and obese; the majority were male and non-Hispanic Black, with more than half reporting an education level of greater than 12 years. No significant differences existed in demographic characteristics between those who consented $(n=114)$ and those who completed the follow-up visit (data not shown); only those who completed the follow-up visit $(n=71)$ are presented.

Heart failure patients had a Parkland score of $5(2,10)$ and a sodium intake of $2,605 \pm 1,416 \mathrm{mg}$ at the initial visit. The low-knowledge group consumed 3,051 $\pm 1,571 \mathrm{mg}$, while the high-knowledge group consumed $2,407 \pm 1,269 \mathrm{mg}(P=0.07)$ (Table 1). Only $32.4 \%$ of patients were accordant to the 2,000 mg cutoff. Differences in sodium knowledge level by education group existed; $78.3 \%$ of those with more than 12 years of education had high knowledge as compared to $41.7 \%$ of those with education level of 12 years or less $(P=0.002)$.

Of the 71 patients, the 42 patients who had prior education with an RDN had a total knowledge score of $7(2.75,10)$, while the 29 patients who had not seen an $\mathrm{RDN}$ scored $5(2,8.5)(P=0.04)$. A total of $49.3 \%$ of patients were able to correctly sort all 12 containers into low- and high-sodium categories, and $47.8 \%$ used labels to guide sorting. More than $75 \%$ were able to correctly state the sodium content from the Nutrition Facts label, and a majority (63.4\%) was aware of the sodium restriction guideline (Table 2).

Of the 29 high-sodium food categories listed on the Block sodium screener, the most commonly consumed food was dairy products (i.e., milk, yogurt), with $48.7 \%$ of patients consuming these products $\geq 3$ times/week at the initial visit. More than $30 \%$ of patients frequently consumed rice dishes $(31.9 \%)$ and potatoes $(30.6 \%)$. Condiments were consumed by $27.8 \%$ of the patients. The top three perceived barriers to intake of a low-sodium diet were "low-sodium food does not taste good" (41.4\%), "eating out of my home is difficult" (25.9\%), and "buying low-sodium foods are expensive" (20.7\%). 
Table 1 Baseline characteristics of heart failure (HF) patients who completed both initial and follow-up visits with a Registered Dietitian Nutritionist*

\begin{tabular}{|c|c|c|c|c|c|}
\hline \multirow{2}{*}{\multicolumn{2}{|c|}{ Characteristics }} & \multirow[b]{2}{*}{$\begin{array}{c}\text { Sample } \\
n=71\end{array}$} & \multicolumn{3}{|c|}{ Sample stratified by baseline knowledge level ${ }^{\dagger}$} \\
\hline & & & $\begin{array}{l}\text { Low Knowledge } \\
\qquad n=25\end{array}$ & $\begin{array}{l}\text { High Knowledge } \\
\qquad n=46\end{array}$ & $P$-value ${ }^{\neq}$ \\
\hline \multicolumn{2}{|c|}{ Age (years) } & $55.5 \pm 13.6$ & $57.8 \pm 13.8$ & $54.2 \pm 13.4$ & 0.28 \\
\hline \multicolumn{6}{|l|}{ Gender } \\
\hline \multicolumn{2}{|l|}{ Male } & $44(62.0)$ & $18(40.9)$ & $26(59.1)$ & 0.20 \\
\hline \multicolumn{2}{|l|}{ Female } & $27(38.0)$ & $7(25.9)$ & $20(74.1)$ & \\
\hline \multicolumn{6}{|l|}{ Race } \\
\hline \multicolumn{2}{|c|}{ Non-Hispanic White } & $18(25.4)$ & $3(16.7)$ & $15(83.3)$ & 0.16 \\
\hline \multicolumn{2}{|c|}{ Non-Hispanic Black } & $45(63.4)$ & $19(42.2)$ & $26(57.8)$ & \\
\hline \multicolumn{2}{|l|}{ Other $^{\S}$} & $8(11.2)$ & $3(27.5)$ & $5(62.5)$ & \\
\hline \multicolumn{6}{|l|}{ Education } \\
\hline \multicolumn{2}{|c|}{$\leq 12$ years } & $24(34.3)$ & $14(58.3)$ & $10(41.7)$ & 0.002 \\
\hline \multicolumn{2}{|c|}{$>12$ years $\|$} & $47(65.7)$ & $10(21.3)$ & $36(78.7)$ & \\
\hline \multicolumn{2}{|c|}{$\mathrm{BMI}\left(\mathrm{kg} / \mathrm{m}^{2}\right)$} & $31.7(8.7)$ & $30.4(7.8)$ & $32.3(9.0)$ & 0.28 \\
\hline \multicolumn{2}{|c|}{$\begin{array}{l}\text { Time since HF diagnosis } \\
\text { (months) }\end{array}$} & $13(3,33)$ & $21(3.5,21)$ & $11.5(3,27.5)$ & 0.56 \\
\hline \multicolumn{2}{|c|}{ Sodium intake (mg/d) } & $2,605 \pm 1,416$ & $3,051 \pm 1,571$ & $2,407 \pm 1,269$ & 0.07 \\
\hline \multicolumn{2}{|c|}{ Sodium accordances } & $23(32.4)$ & $5(21.7)$ & $18(78.3)$ & 0.10 \\
\hline \multirow{2}{*}{\multicolumn{6}{|c|}{$\begin{array}{l}{ }^{*} \text { Values are mean } \pm \text { SD or median (IQR) for continuous variables, and } \mathrm{n}(\%) \text { for categorical variables, respectively. } \\
\text { } \text { Low and high knowledge is defined as having a Parkland Sodium Knowledge score between } 0 \text { to } 3 \text { and } 5 \text { to } 10 \text { points, } \\
\text { respectively. Knowledge score of the sample at the initial visit was } 5(2,10) \text {. } \\
\text { "Data with mean } \pm \text { SD: } P \text { values determined by Independent } t \text {-tests between knowledge groups. Data with } \mathrm{n}(\%) \text { : } P \text {-values } \\
\text { determined by } \chi^{2} \text { tests between knowledge groups. } P \text { value }<0.05 \text { considered statistically significant. } \\
\text { } \text { Other includes Hispanic and Asian/Pacific Islander. } \\
\text { "Three patients refused to answer, } \mathrm{n}=68 \text {. } \\
\text { 'Percent accordant was defined by having sodium intake }<2,000 \mathrm{mg} / \mathrm{d} \text { as assessed by NutritionQuest }{ }^{\oplus} \text { Block Sodium Screener. } \\
\text { Table } 2 \text { Change in the Parkland Sodium Knowledge Test components among } 71 \text { heart } \\
\text { failure patients receiving education by a Registered Dietitian Nutritionist during } \\
\text { their first visit }\end{array}$}} \\
\hline & & & & & \\
\hline \multicolumn{3}{|c|}{ Components of Parkland Sodium Knowledge Test ${ }^{*}$} & $\begin{array}{c}\text { Initial Visit } \\
n(\%)\end{array}$ & $\begin{array}{c}\text { Follow-Up Visit } \\
n(\%)\end{array}$ & $P$-value ${ }^{\dagger}$ \\
\hline \multicolumn{6}{|c|}{ Number of Containers Correctly Sorted } \\
\hline \multicolumn{2}{|l|}{$\leq 11$} & & $36(50.7)$ & $24(33.8)$ & 0.01 \\
\hline \multicolumn{2}{|l|}{12} & & $35(49.3)$ & $47(66.2)$ & \\
\hline \multicolumn{6}{|c|}{ Containers Correctly Sorted } \\
\hline \multicolumn{6}{|c|}{ Low-Sodium } \\
\hline \multicolumn{2}{|c|}{ Frozen vegetable } & & $69(97.2)$ & $67(94.3)$ & 0.62 \\
\hline \multicolumn{2}{|c|}{ Frozen fruit } & & $68(95.8)$ & $67(94.3)$ & 1.00 \\
\hline \multicolumn{2}{|c|}{ Salt-free seasoning blend } & & $66(93.0)$ & $65(91.5)$ & 1.00 \\
\hline \multicolumn{2}{|l|}{ Beans } & & $63(88.7)$ & $67(94.3)$ & 0.29 \\
\hline Potatoe & & & $60(84.7)$ & $61(85.9)$ & 1.00 \\
\hline Rice & & & $55(77.5)$ & $64(90.1)$ & 0.01 \\
\hline High-Sodi & & & & & \\
\hline Sausage & & & $69(97.2)$ & $71(100.0)$ & - \\
\hline Soup & & & $69(97.2)$ & 68 (95.8) & 1.00 \\
\hline
\end{tabular}


Table 2 Continued

\begin{tabular}{lccc}
\hline Components of Parkland Sodium Knowledge Test & $\begin{array}{c}\text { Initial Visit } \\
\boldsymbol{n}(\%)\end{array}$ & $\begin{array}{c}\text { Follow-Up Visit } \\
\boldsymbol{n}(\%)\end{array}$ & $\boldsymbol{P}^{*}$-value $^{\dagger}$ \\
\hline Frozen TV dinner & $67(94.3)$ & $70(98.6)$ & 0.25 \\
$\quad$ Macaroni and cheese & $66(93.0)$ & $66(93.1)$ & 1.00 \\
$\quad$ Instant noodles & $65(91.5)$ & $68(95.8)$ & 0.25 \\
$\quad$ Pretzels & $65(91.5)$ & $70(98.6)$ & 0.06 \\
Used Label to Guide Sorting & $34(47.8)$ & $22(31.0)$ & 0.02 \\
Stated Sodium Content Correctly from Label & $55(77.5)$ & $57(80.3)$ & 0.77 \\
Knew the Sodium Guideline & $45(63.4)$ & $51(71.8)$ & 0.29 \\
Parkland Knowledge Score & $5(2,10)$ & $7.5(5,10)$ & 0.003 \\
Low Knowledge & & & 0.01 \\
$\quad$-3 & $25(35.2)$ & $15(21.1)$ & \\
High Knowledge & & & \\
5-8 & $21(29.6)$ & $23(32.3)$ & \\
10 & $25(35.2)$ & $33(46.5)$ & \\
\hline
\end{tabular}

*The Parkland Sodium Knowledge Test is a questionnaire designed to test the patients' knowledge of low-sodium diet. The questionnaire consists of 8 questions with scoring options of $2,3,5,7$, and 10.

${ }^{\dagger} \mathrm{McNemar}$ 's test performed between initial and follow-up visit.

*The maximum possible score on Parkland is 10 points. Low knowledge was a score of $0-3$, while high knowledge was indicated by a score between 5 and 10. Points per questionnaire component is as follows: 12 containers sorted correctly, 5 points; correctly stated sodium content from provided example label, 2 points; knew the sodium guideline, 3 points.

\section{Change in sodium knowledge and intake after RDN education}

The median follow-up time was $5(3,8)$ months. No difference in sodium knowledge by follow-up time existed when those above and below the median follow-up time were compared. When HF patients were divided into low knowledge (score of 0-3) and high knowledge (score of 5-10) groups at follow-up, those in the low knowledge group were older $(P=0.02)$, less educated $(P=0.02)$, and had a higher intake of sodium than the high knowledge group $(2,783 \pm 1,526$ versus $1,996 \pm 1,111 \mathrm{mg}$, respectively; $P=0.03)$.

The Parkland score significantly increased from $5(2,10)$ to $7.5(5,10)(P=0.003)$, with $46.5 \%$ achieving a perfect score of 10 at the follow-up visit (Table 2). The proportion of patients who were able to correctly sort all 12 containers increased to $66.2 \%(P=0.01)$. Correctly sorted food containers were similar between visits, except for an increase in those that correctly sorted rice $(77.5 \%$ to $90.1 \%$; $P=0.01)$. Those who used the Nutrition Facts label to guide sorting decreased from $47.8 \%$ to $31.0 \%$ $(P=0.02)$.

Sodium intake significantly decreased from $2,605 \pm 1,416$ to $2,134 \pm 1,254 \mathrm{mg}$ ( $18 \%$ reduction, $P=0.001$ ), with $56.3 \%$ consuming less than $2,000 \mathrm{mg}$ after education. At the follow-up visit, the proportion of patients consuming foods within the 29 high-sodium food categories decreased overall (e.g., lunchmeat consumption decreased by $41 \%$ ).
However, the only decrease was in condiment consumption, from $27.8 \%$ to $15.3 \%(P=0.049)$.

\section{Relationship between change in sodium knowledge and adherence}

The sample was stratified based on change in knowledge, either an increase in knowledge or no change in knowledge; the group categorized as no change consisted of either a decrease or no change in the Parkland knowledge score. Those who had an increase in their knowledge score had a score of 2.5 $(2,5)$ at the initial visit, which increased to $7.5(5,10)$ at the follow-up visit $(P<0.001)$. These patients also reduced their sodium intake from $2,806 \pm 1,472 \mathrm{mg}$ to $2,091 \pm 1,170 \mathrm{mg}(P=0.01)$. In addition, those who had a decrease or no change in the Parkland score consumed $2,522 \pm 1,368 \mathrm{mg}$ at the initial visit and $2,209 \pm 1,297 \mathrm{mg}$ at follow-up visit $(P<0.001)$.

The sample was also stratified based on median change in sodium intake ( $472 \mathrm{mg}$ decrease), with groups defined by a decrease of $<500 \mathrm{mg}$ or a decrease of $\geq 500 \mathrm{mg}$. Both groups had an improved knowledge score after education, but only those who had a decrease in sodium intake of $\geq 500 \mathrm{mg}$ had a increase in knowledge from $5(2,10)$ to 7.5 $(5,10)(P=0.003)$.

\section{Change in barriers to low-sodium diet adherence}

While barriers to low-sodium diet adherence did not significantly change, the majority of barriers to 


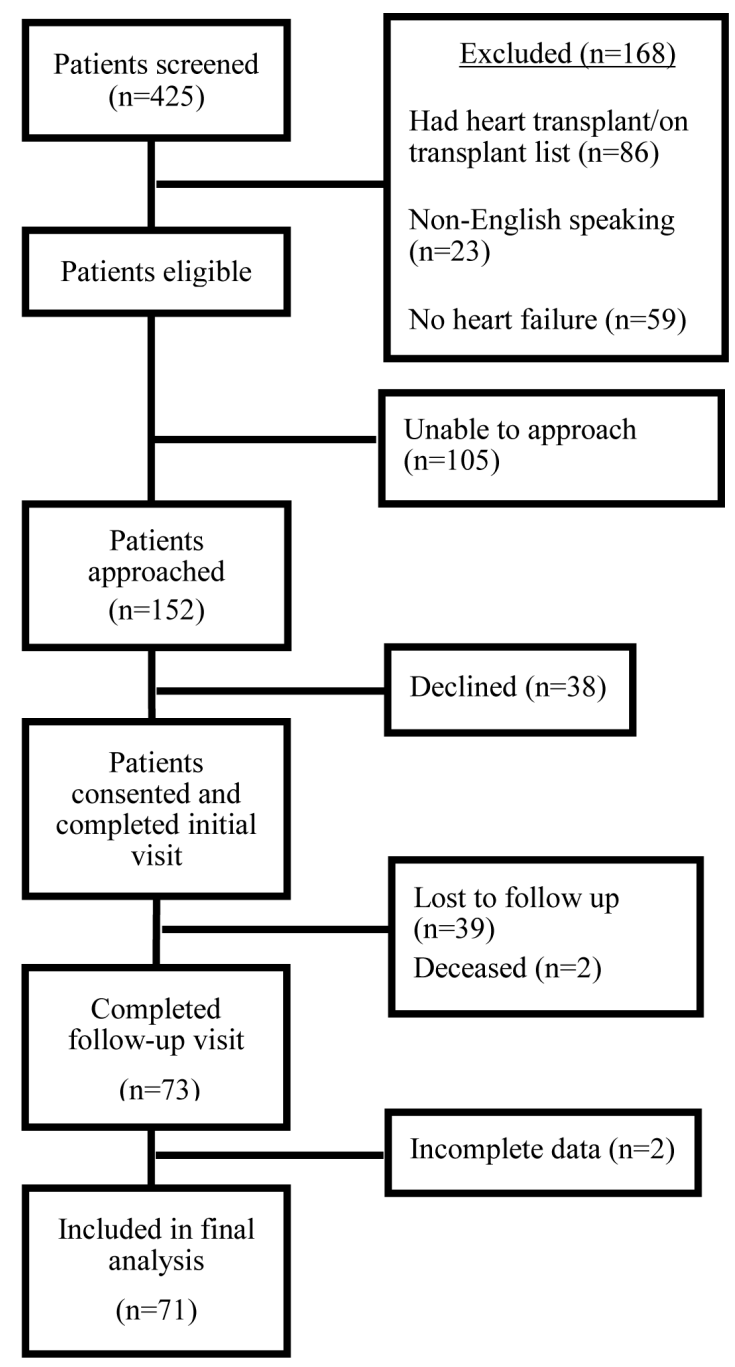

Figure 1. Flow chart of heart failure patient recruitment and enrollment.

following a LSD decreased, including "low-sodium food doesn't taste good" (from 41.4\% to 37.9\%) and buying low-sodium foods are expensive" (from $20.7 \%$ to $15.5 \%$ ). One perceived barrier to low-sodium food consumption, "eating outside of my home is difficult," increased from $25.9 \%$ to $29.3 \%$.

\section{DISCUSSION}

The major finding of this outpatient HF clinic study was that an RDN is effective in improving sodium knowledge and reducing sodium intake through tailored nutrition education. While this sample was knowledgeable, they were not accordant to the LSD at baseline. After nutrition education, sodium intake was significantly reduced by approximately $500 \mathrm{mg}$, increasing adherence from $32 \%$ to $56 \%$ after RDN education.

The 25\% improvement seen in the Parkland knowledge score after nutrition education by an
RDN was largely driven by improvement in the ability to sort 12 containers correctly into high- and low-sodium categories. Heart failure patients were less able to identify low-sodium containers at the initial visit. Patients may be preparing low-sodium foods such as potatoes and rice with high-sodium condiments and dressings, or consuming them in processed form, influencing how patients perceive sodium in these food items. Thus, RDNs may focus patient education on identification of low-sodium foods and how they differ from high-sodium versions. No change in ability to read the sodium content on the food labels was seen with RDN education, a finding dissimilar to Neily et al. ${ }^{13}$ This may indicate that foods were sorted based on knowledge gained through RDN education at the first visit, a finding further supported by the less frequent use of the nutrition fact label at the follow-up visit.

Baseline sodium knowledge and education level were associated, and patients who had more than 12 years of education were more likely to be knowledgeable. This was consistent with knowledge after education, as those in the high knowledge group at follow-up were also more educated. As those in the high knowledge group were also younger, this indicates that provider knowledge of both patient education level and age may be important to help tailor strategies to retain sodium knowledge-related information.

After nutrition education, the magnitude of sodium reduction was similar to previously reported reductions in sodium with RDN-led interventions. ${ }^{18,20}$ In the current study, those who had an increase in knowledge had an estimated 800 mg sodium reduction compared to an estimated $300 \mathrm{mg}$ sodium reduction in those with no change or decrease in knowledge. However, the baseline knowledge score in the group that had no change or decrease in knowledge with RDN education was 10 , which is the maximal score; this indicated a high level of baseline knowledge. This may explain the minimal change in sodium intake in this group (2,522 $\mathrm{mg}$ to $2,209 \mathrm{mg}$ ) and suggests that an RDN is most effective in helping to lower sodium intake in those with lower baseline sodium knowledge but may still invoke a smaller but beneficial reduction in sodium intake in those that already have high knowledge. In addition to the potential influence of knowledge on sodium intake, barriers such as those addressed in this study may influence the ability to reduce sodium intake. Barriers identified in the current study were similar to other studies, ${ }^{10,14,21}$ and the lack of significant change in these barriers suggests that one nutrition consultation may not be enough to completely overcome these other barriers 
to following this diet. Repeated visits would allow an RDN to focus on strategies to improve accordance, including behavior change and motivational interviewing techniques to identify internal motivation to facilitate change.

This study has several limitations, including the lack of a control group that did not receive RDN-administered education. While predicted sodium intake from the sodium screener correlated with 24-hour recall sodium estimates in two samples, agreement between the sodium screener and 24-hour recalls was poor when individuals were classified as meeting sodium intake guidelines or not. ${ }^{22}$ Thus, additional testing of the sodium screener may be needed in this population to identify the degree to which sodium estimates represent intake. However, 24-hour urinary sodium excretion or food records were not feasible in this study with the limited amount of time during the visit and the burden of urine collection; indeed, accurately estimating sodium intake in those with HF may result in biased data, ${ }^{23}$ and the use of the current screener does not fully address this concern.

Lastly, current sodium guidelines for heart failure patients vary depending on association, stage of heart failure, and diuretic therapy, with restriction ranging from 1,500 to $3,000 \mathrm{mg} /$ day. ${ }^{7,8}$ Thus, our selection of $2,000 \mathrm{mg} / \mathrm{d}$ to define accordance/ adherence may not apply to all heart failure patients. Additionally, more research is needed to confirm the use of a restricted sodium diet for those with $\mathrm{HF}^{24}$ Several ongoing clinical trials (PROHIBITSodium, SODIUM-HF) may inform the appropriate sodium intake levels for patients with $\mathrm{HF}^{25,26}$

In conclusion, RDN-led nutrition education contributed to improved knowledge scores and sodium intakes in patients with HF. Baseline sodium knowledge and education level are important components that contribute to sodium intake; these factors should be considered when RDN education is administered. As sodium intake may not always directly relate to sodium knowledge, RDNs should use appropriate behavior change models to address other factors influencing adherence. In addition, tools such as the Parkland, NutritionQuest ${ }^{\oplus}$ sodium screener, and a list of barriers are helpful to individualize nutrition education to generate positive lifestyle changes. Incorporation of an RDN into a multidisciplinary team to provide support for these changes may be warranted.

\section{ACKNOWLEDGEMENTS}

The authors would like to acknowledge Melanie Betz, MS, RD for her assistance in patient recruitment and education at Rush University Medical Center.

\section{REFERENCES}

1. Heart Disease and Stroke Statistics-2019 Update: A Report From the American Heart Association | Circulation n.d. https://www.ahajournals.org/doi/10.1161/ CIR.0000000000000659 (accessed September 30, 2019).

2. Sacks FM, Svetkey LP, Vollmer WM, Appel LJ, Bray GA, Harsha D, et al. Effects on blood pressure of reduced dietary sodium and the Dietary Approaches to Stop Hypertension (DASH) diet. DASH-Sodium Collaborative Research Group. N Engl J Med 2001;344:3-10. doi:10.1056/ NEJM200101043440101.

3. Toledo E, Hu FB, Estruch R, Buil-Cosiales P, Corella D, Salas-Salvadó J, et al. Effect of the Mediterranean diet on blood pressure in the PREDIMED trial: results from a randomized controlled trial. BMC Med 2013;11:207. doi:10.1186/1741-7015-11-207.

4. Shai I, Schwarzfuchs D, Henkin Y, Shahar DR, Witkow S, Greenberg I, et al. Weight Loss with a Low-Carbohydrate, Mediterranean, or Low-Fat Diet. N Engl J Med 2008;359:229-41. doi:10.1056/NEJMoa0708681.

5. Estruch R, Ros E, Salas-Salvadó J, Covas M-I, Corella D, Arós F, et al. Primary Prevention of Cardiovascular Disease with a Mediterranean Diet Supplemented with ExtraVirgin Olive Oil or Nuts. N Engl J Med 2018;378:e34. doi:10.1056/NEJMoa1800389.

6. Knowler WC, Barrett-Connor E, Fowler SE, Hamman RF, Lachin JM, Walker EA, et al. Reduction in the incidence of type 2 diabetes with lifestyle intervention or metformin. N Engl J Med 2002;346:393-403. doi:10.1056/ NEJMoa012512.

7. Heart Failure Society of America, Lindenfeld J, Albert NM, Boehmer JP, Collins SP, Ezekowitz JA, et al. HFSA 2010 Comprehensive Heart Failure Practice Guideline. J Card Fail 2010;16:e1-194. doi:10.1016/j.cardfail.2010.04.004.

8. Yancy CW, Jessup M, Bozkurt B, Butler J, Casey DE Jr, Drazner $\mathrm{MH}$, et al. 2013 ACCF/AHA guideline for the management of heart failure: a report of the American College of Cardiology Foundation/American Heart Association Task Force on Practice Guidelines. J Am Coll Cardiol 2013;62:e147-239. doi:10.1016/j. jacc.2013.05.019.

9. Ni H, Nauman D, Burgess D, Wise K, Crispell K, Hershberger RE. Factors influencing knowledge of and adherence to self-care among patients with heart failure. Arch Intern Med 1999;159:1613-9.

10. Lennie TA, Worrall-Carter L, Hammash M, OdomForren J, Roser LP, Smith CS, et al. Relationship of heart failure patients' knowledge, perceived barriers, and attitudes regarding low-sodium diet recommendations to adherence. Prog Cardiovasc Nurs 2008;23:6-11.

11. van der Wal MH, Jaarsma T, van Veldhuisen DJ. Noncompliance in patients with heart failure; how can we manage it? Eur J Heart Fail 2005;7:5-17.

12. Kollipara UK, Jaffer O, Amin A, Toto KH, Nelson LL, Schneider R, et al. Relation of lack of knowledge about dietary sodium to hospital readmission in patients with heart failure. Am J Cardiol 2008;102:1212-5. doi:10.1016/j. amjcard.2008.06.047.

13. Neily JB, Toto KH, Gardner EB, Rame JE, Yancy CW, Sheffield MA, et al. Potential contributing factors to noncompliance with dietary sodium restriction in patients with heart failure. Am Heart J 2002;143:29-33.

14. Nieuwenhuis MM, van der Wal MH, Jaarsma T. The body of knowledge on compliance in heart failure patients: we are not there yet. J Cardiovasc Nurs 2011;26:21-8. doi:10.1097/JCN.0b013e3181e27a2d.

15. van der Wal MH, Jaarsma T, Moser DK, Veeger NJ, van Gilst WH, van Veldhuisen DJ. Compliance in heart failure patients: the importance of knowledge and beliefs. Eur Heart J 2006;27:434-40.

16. van der Wal MH, Jaarsma T, Moser DK, van Gilst WH, van Veldhuisen DJ. Unraveling the mechanisms for heart failure patients' beliefs about compliance. Heart Lung J Crit Care 2007;36:253-61. 
17. Colin-Ramirez E, McAlister FA, Woo E, Wong N, Ezekowitz JA. Association between self-reported adherence to a low-sodium diet and dietary habits related to sodium intake in heart failure patients. J Cardiovasc Nurs 2015;30:58-65. doi:10.1097/JCN.0000000000000124.

18. Arcand JA, Brazel S, Joliffe C, Choleva M, Berkoff F, Allard JP, et al. Education by a dietitian in patients with heart failure results in improved adherence with a sodium-restricted diet: a randomized trial. Am Heart J 2005;150:716.

19. Kollipara UK, Mo V, Toto KH, Nelson LL, Schneider RA, Neily JB, et al. High-sodium food choices by southern, urban African Americans with heart failure. J Card Fail 2006;12:144-8.

20. Kuehneman T, Saulsbury D, Splett P, Chapman DB. Demonstrating the impact of nutrition intervention in a heart failure program. J Am Diet Assoc 2002;102:1790-4.

21. Heo S, Lennie TA, Moser DK, Okoli C. Heart failure patients' perceptions on nutrition and dietary adherence. Eur J Cardiovasc Nurs J Work Group Cardiovasc Nurs Eur Soc Cardiol 2009;8:323-8. doi:10.1016/j. ejcnurse.2009.05.005.

22. Tangney CC, Rasmussen HE, Richards C, Li M, Appelhans BM. Evaluation of a Brief Sodium Screener in Two Samples. Nutrients 2019;11. doi:10.3390/nu11010166.

23. Colin-Ramirez E, Arcand J, Ezekowitz JA. Estimates of Dietary Sodium Consumption in Patients with Chronic Heart Failure. J Card Fail 2015;21:981-8. doi:10.1016/j. cardfail.2015.08.345.
24. Mahtani KR, Heneghan C, Onakpoya I, Tierney S, Aronson JK, Roberts N, et al. Reduced Salt Intake for Heart Failure: A Systematic Review. JAMA Intern Med 2018;178:1693-700. doi:10.1001/ jamainternmed.2018.4673.

25. Butler J, Papadimitriou L, Georgiopoulou V, Skopicki H, Dunbar S, Kalogeropoulos A. Comparing Sodium Intake Strategies in Heart Failure: Rationale and Design of the Prevent Adverse Outcomes in Heart Failure by Limiting Sodium (PROHIBIT) Study. Circ Heart Fail 2015;8:63645. doi:10.1161/CIRCHEARTFAILURE.114.001700.

26. Colin-Ramirez E, Ezekowitz JA, SODIUM-HF investigators. Rationale and design of the Study of Dietary Intervention Under $100 \mathrm{MMOL}$ in Heart Failure (SODIUM-HF). Am Heart J 2018;205:87-96. doi:10.1016/j. ahj.2018.08.005.

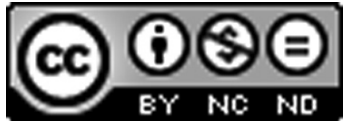

This work is licensed under a Creative Commons Attribution-Non Commercial-No Derivatives 4.0 International License. To view a copy of this license, visit http://creativecommons.org/licenses/by-nc-nd/4.0/ 